\title{
ANÁLISE SOBRE O USO DAS TECNOLOGIAS DIGITAIS DA INFORMAÇÃO E COMUNICAÇÃO (TDICS) NO PROCESSO EDUCACIONAL DA GERAÇÃO INTERNET
}

\author{
Silvia Cota Machado, CEFET/MG, silviac.ti@gmail.com
}

\begin{abstract}
Resumo: O uso de Tecnologias Digitais da Informação e Comunicação (TDICs) altera o processo educacional dos estudantes da era digital. Um dos maiores desafios do professor do Século XXl é entender as demandas e incorporá-las nas práticas pedagógicas. O espaço de aprendizagem formado por alunos interativos e conectados ganha uma nova abordagem: a aprendizagem colaborativa. Nesta perspectiva o objetivo da pesquisa foi, através da aplicabilidade de Blogs e videoaulas no ambiente de aprendizagem, relatar a experiência no uso de TDICs como instrumento mediador no processo educacional e as percepções dos alunos ao utilizá-las. O método de pesquisa foi um estudo de caso realizado com estudantes de uma instituição de ensino em Belo Horizonte-MG. O instrumento de pesquisa foi o questionário. Os resultados indicam quais tecnologias podem ser adotadas para complementar as aulas e quais são consideradas mais relevantes pelos alunos, aqui chamados de Geração Internet.
\end{abstract}

Palavras-chave: Tecnologias Digitais, Geração Internet, Educação, Aprendizagem colaborativa.

Abstract: The use of Information and Communication Digital Technologies (ICDTs) alters the educational process of the Net Generation students. One of the biggest challenges for the teacher in the XXIst century is to understand the demands and incorporate them in pedagogical practices. The learning environment that consisting of students interactive and connected has gained a new approach: collaborative learning. In this perspective the objective was report the experience of using ICDTs as a mediator instrument in the educational process by means of compound the applicability of Blogs and video classes in the learning environment and the perception of students regarding use of these technologies. The method used was a case study with students of educational institution in Belo Horizonte-MG. The research instrument was a questionnaire. The results demonstrate which technologies can be adopted to complement classes and which are considered the most relevant for the student, that we call the Internet Generation.

Keywords: Digital Technologies, Internet Generation, Education, Collaborative learning.

\section{Introdução}

O Século XXI é marcado por mudanças significativas na educação e aprendizagem. O uso das Tecnologias Digitais de Informação e Comunicação (TDICs) pelas gerações nascidas no final do século $\mathrm{XX}$ vem transformando o processo educacional. Dentre essas transformações encontra-se a mudança no modelo pedagógico que, segundo Tapscott (2010), passou de uma abordagem focada no professor para um modelo focado no estudante e baseado na colaboração. Uma vez que esta geração convive naturalmente com as tecnologias digitais, suas influências trouxeram para os ambientes escolares alunos mais interativos e conectados. Diante deste contexto faz-se 
necessário um novo olhar sobre este espaço de convivência entre alunos e professores de diferentes gerações.

A década de 1990 foi marcada pela popularização do computador pessoal e da internet. Na mesma época, surgiram os termos TICs (Tecnologias da Informação e Comunicação) e TDICs, integrando as mídias digitais no conjunto de recursos tecnológicos de informação e comunicação. Castells (1999) previra esse cenário quando observou o surgimento de um novo sistema eletrônico de comunicação caracterizado pelo seu alcance global e a integração de todos os meios de comunicação, essa interatividade mudaria para sempre nossa cultura.

Ainda nessa época, a primeira geração da internet, a Web 1.0 era composta por sites estáticos e não interativos. Visitar uma página significava ler sua informação, mas não era possível interagir com ela. Alguns anos mais tarde, em 2004, surgiu a Web 2.0, termo criado por Tim O'Reilly (2005); considerada um marco no aprendizado virtual por tratar-se de uma plataforma colaborativa. Seu principal objetivo é o aproveitamento da inteligência coletiva, pois a rede permite que as pessoas criem seu próprio conteúdo, colaborem entre si e construam comunidades. Os principais exemplos de aplicações Web 2.0 são o Facebook, Youtube, Wikipedia e Blogger. Mais recente, surgiu a Web 3.0 ou Web Semântica; é a terceira geração da internet. Esta nova geração propõe organizar os conteúdos online de forma semântica, mais personalizados para cada internauta, sites e aplicações inteligentes, além de publicidade baseada nas pesquisas e comportamentos.

Como delineado anteriormente, pode-se perceber que o século XXI vem sendo marcado por mudanças sociais que afetam principalmente a geração nascida após os anos 90. Seguindo esta linha pode-se inferir que, dentre as inúmeras transformações, tais mudanças afetam também a educação e os sistemas de ensino e faz-se necessário entender como as tecnologias digitais podem beneficiar alunos e professores no processo de construção do conhecimento científico e acadêmico. Castells (2000), conjectura que no final do século XX vivemos um raro intervalo de tempo na história, cuja característica foi a transformação da "cultura material" por um novo paradigma tecnológico que se organizou em torno da tecnologia da informação.

Não há dúvidas que as TDICs provocam mudanças consideráveis na forma de ensinar e aprender transformando o processo educacional tradicional, antes passivo, em aprendizado interativo. Utilizada de maneira criativa, a tecnologia pode tornar a aula prazerosa e atrativa. Como propõe Faria (2008), isto implica em uma análise da mudança do paradigma educacional e da função do professor na relação pedagógica, focalizando as inovações tecnológicas como ferramentas para ampliar a interação e a interatividade.

\section{Aprendizagem colaborativa mediada pelo uso das TDICs}

\subsection{A Geração Internet}

Conforme Tapscott (2010), os jovens da Geração Internet nasceram em meados dos anos 90 e cresceram em um ambiente digital, dessa forma, a escola para estes jovens representa um espaço de formação e geração de conhecimento. Definir e organizar o conteúdo pedagógico neste espaço mediado pelo uso dos recursos tecnológicos não é tarefa fácil, entretanto, faz-se necessário repensar um modelo educacional que incentive a construção do conhecimento de maneira colaborativa. Conforme (COLL, 2010), não há dúvidas que,

[...] a interação entre a mente dos agentes educacionais e um sistema complexo de processamento e transmissão de informação, como é a internet, está modificando de maneira significativa as ferramentas, os cenários e as 
finalidades da educação neste começo do século XXI. (COLL, MONEREO, 2010 p.21)

A sociedade da informação traz contribuições relevantes para a educação, ensino e aprendizagem. Segundo Castells (2000), o que caracteriza a atual revolução tecnológica não é a centralidade de conhecimentos e informação, mas a aplicação desses conhecimentos e informação para a geração de novos conhecimentos perfazendo um ciclo baseado na colaboração.

O modelo de educação do século XXI tem como característica a capacidade de aprender e ensinar colaborativamente mediado pelo uso de tecnologias. Entretanto, os educadores seguem um modelo de ensino que eles aprenderam - unidirecional, rígido, centrado no professor. A figura abaixo mostra a diferença entre o aprendizado centrado no professor e o aprendizado interativo.

Quadro 1: Aprendizado de massa em comparação com aprendizado interativo

\begin{tabular}{|c|c|}
\hline APRENDIZADO DE MASSA & APRENDIZADO INTERATIVO \\
\hline Centrado no professor & Centrado no estudante \\
\hline Padronizado & Personalizado \\
\hline Centralidade de conhecimento e informação & $\begin{array}{c}\text { Construção do conhecimento através da } \\
\text { colaboração }\end{array}$ \\
\hline Aprendizado individualista & Aprendizado colaborativo \\
\hline Aulas expositivas & Aulas interativas \\
\hline
\end{tabular}

Fonte: Adaptado de Tapscott (2010, p.163)

O aprendizado em massa para Tapscott (2010), pode ser comparado ao modelo de educação da era industrial e esse deve ser abandonado e substituído por um modelo centrado no aluno, em vez de dar aulas expositivas, os professores deveriam interagir com os alunos e ajuda-los a ser protagonistas no processo de aprendizagem.

Os jovens da Geração Internet cresceram em um ambiente digital e estão vivendo no século XXI, mas o sistema educacional em muitos lugares está pelo menos cem anos atrasado. O modelo de educação que ainda prevalece hoje foi projetado para a Era Industrial. (TAPSCOTT, 2010, p. 149).

Para Tapscott (2010), o que importa não é mais o que você sabe, mas o que você pode aprender. Isso significa que os jovens da Geração Internet precisam de uma forma de educação diferente da que os baby boomers ${ }^{l}$ receberam. Pois, como afirma Coll (2010),

Quanto ao papel de professores e alunos e às formas de interação que as TIC propiciam, as mudanças também parecem irreversíveis. A imagem do professor transmissor de informação, protagonista central das trocas entre seus alunos e guardião do currículo começa a entrar em crise em um mundo conectado por telas de computador. (COLL, MONEREO, 2010, p.31)

E ainda, Prensky (2008) colabora ao afirmar que a velha pedagogia centrada no professor precisa ser substituída pela nova pedagogia baseada na aprendizagem centrada no aluno, em que o aluno ensina a si mesmo com o apoio da tecnologia, mas orientado pelo professor.

\subsection{Aprendizagem colaborativa}

Segundo Tapscott (2010) a Geração Internet utiliza a comunidade virtual para encontrar e compartilhar informações. Essa geração está transformando a internet em 
um lugar para compartilhar e se relacionar, assim como o ambiente escolar deixou de ser um espaço para aprendizado e tornou-se um espaço para construção coletiva do conhecimento. Por isso, o papel do professor não é de ensiná-los alguma coisa, e sim, conduzi-los como mediadores no processo de aprendizagem e descobertas.

Nas palavras de Lévy (1999), o papel do professor não pode ser apenas de transferência do conhecimento e sim de "animador da inteligência coletiva" dos grupos de estudantes. Ou seja, as atividades são orientadas pelos princípios da "inteligência coletiva" proposta por Lévy (1999) utilizando-se de ambientes colaborativos e mediados pelas TDICs. Ainda, segundo Kenski (2003),

\begin{abstract}
[...] as atividades colaborativas de ensino orientam-se pelos princípios da "inteligência coletiva", proposta por Lévy (1999), e correspondem “à reunião em sinergia dos saberes, das imaginações, das energias espirituais... de um grupo humano constituído como comunidade virtual". (Lévy,1999, apud KENSKI, 2003, p.128)
\end{abstract}

A capacidade de aprender novas coisas é mais importante que nunca em um mundo onde as fontes de conhecimento não são mais os professores, e sim a internet. Estes jovens cresceram em um ambiente digital, são considerados nativos digitais, por isso, não se contentam mais em ficar passivos à aula expositiva do professor.

\title{
2. Metodologia
}

Baseado na proposta de Kenski (2009), o objetivo do trabalho foi ampliar o uso das tecnologias digitais no processo educacional a partir de um projeto pedagógico baseado no desenvolvimento de blogs, sites e videoaulas durante as aulas da disciplina Informática Aplicada do Curso Técnico em Informática nos anos de 2014/2015. Observou-se neste período que o uso das TDICs como recurso pedagógico no processo de ensino e aprendizagem orientado pelo professor trouxe mudanças consideráveis e positivas durante as práticas educacionais desses jovens, aqui chamados de Geração Internet (Machado, 2015).

Através da pesquisa buscou-se perceber o interesse destes alunos pelas TDICs em atividades educacionais e verificar quais recursos das TDICs os alunos e professores da instituição utilizavam em sala de aula, e ainda, despertar o interesse pelo tema e incentivar futuras investigações. Os questionários foram aplicados após o término das atividades, abrangendo 117 alunos. Durante as práticas foram utilizados diversos recursos digitais para comunicação entre os alunos e a professora. Além dos laboratórios da escola, os alunos puderam interagir e fazer as atividades fora do ambiente escolar através de seus dispositivos pessoais (Notebook, tablet, e smartphone).

A metodologia de pesquisa empregada para a realização deste estudo foi descritiva com abordagem qualitativa. Quanto aos meios de investigação, este estudo se caracteriza como estudo de caso, sendo que o instrumento de coleta de dados utilizado foi um questionário, composto por questões que abordam os 7 (sete) temas a seguir:

a) Faixa etária dos alunos;

b) Quais tecnologias seus professores utilizam em sala de aula;

c) Recursos tecnológicos utilizados pelos alunos em sala de aula;

d) Tecnologias utilizadas pelos alunos para complementar os estudos;

e) Recursos tecnológicos disponibilizados pela universidade;

f) Tecnologias de comunicação utilizadas para interação aluno/aluno e aluno/professor;

g) A percepção dos alunos sobre as aulas presenciais. 
No total, foram aplicados 117 questionários e teve como público alvo alunos matriculados em 4 turmas do primeiro período do curso Técnico em Informática, entre Maio/2014 e Março/2015. O retorno de questionários respondidos foi de $100 \%$.

\subsection{Perfil dos entrevistados}

Quanto à faixa etária dos alunos respondentes, 73,5\% estava compreendida entre 18 e 24 anos, 21,4\% representam a faixa entre 24 e 35 anos e 5,1\% acima de 35 anos.

Pela faixa etária dos respondentes, pode-se afirmar que estes alunos representam perfeitamente, em sua maioria, a Geração Internet.

\subsection{Infraestrutura Tecnológica da Instituição}

Verificou-se que a instituição de ensino disponibilizava acesso à internet via rede $w i$ - $f i$ para $100 \%$ dos alunos, permitindo que estes pudessem utilizar seus próprios dispositivos móveis nas aulas, além de laboratórios equipados com 1 computador por aluno. A instituição também oferecia aos professores acesso à internet, notebook e salas de aula equipadas com recursos audiovisuais. A comunicação entre alunos e professores também acontecia através do Sistema On Line (SOL), possibilitando aos professores o compartilhamento de material didático digital.

Através do gráfico 1, pode-se inferir que $86,3 \%$ dos alunos utilizavam os laboratórios do curso em questão. Percebe-se ainda que 65,8\% dos alunos utilizavam seus smartphones nas aulas, comprovando a necessidade destes jovens se manterem online através de seus aparelhos móveis. Apenas $23 \%$ dos alunos utilizavam notebook. Os alunos justificaram que os aparelhos celulares têm quase todos os recursos que eles necessitam.

Gráfico 1: Recursos tecnológicos utilizados pelos alunos para assistir as aulas.

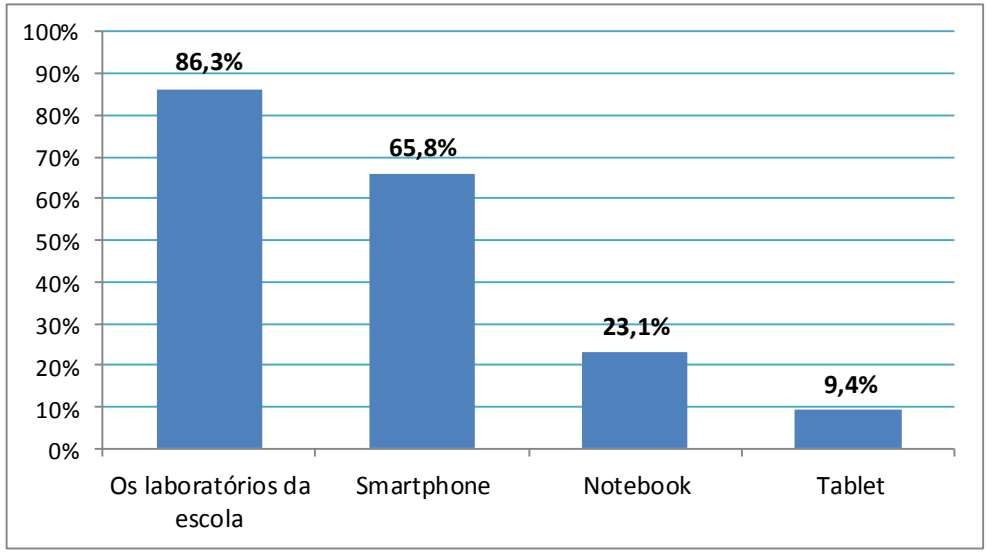

Fonte: dados da pesquisa

\subsection{Tecnologias utilizadas pelos professores em sala de aula.}

Ao questionar os alunos sobre o uso das tecnologias pelos professores em suas aulas, estes responderam que $47,9 \%$ de seus professores utilizavam TDICs nas aulas e ainda, quando questionados sobre a importância do uso de TDICs em sala de aula, os alunos responderam Sim 98,3\% (acham importante) e 1,7\% Não (não acham importante). Ou seja, mesmo com infraestrutura e recursos suficientes, os professores utilizam as TDICs bem abaixo do desejado pelos alunos do curso.

Durante as práticas, foram utilizados Filmes e vídeos como recurso pedagógico, além de videoaulas e material digital disponibilizado nos blogs. Através do gráfico 2 pode-se auferir que dentre as TDICs que os alunos mais se sentem atraídos estão os 
Simuladores 63,2\%, Apostilas Digitais 60,7\%, Vídeos 59,8\% e Filmes (41\%). Estes dados comprovam que os vídeos ainda são recursos atrativos para os alunos como defendido por Moran (1995). As apostilas digitais e tutoriais também são recursos atrativos, pois permitem sua visualização através de smartphones e tablets a qualquer momento.

Para as práticas em sala de aula foram utilizados vídeo-aulas e tutoriais criados pelos alunos e disponibilizados através dos blogs das turmas. Os blogs foram criados pelos alunos sob a orientação da professora. Como afirma Tapscott (2010),

[...] quando escrevem em seus blogs ou carregam um vídeo na internet, eles têm a oportunidade de sintetizar e criar uma nova formulação, o que gera uma enorme oportunidade. A Geração Internet teve a chance de satisfazer seu potencial intelectual inerente como nenhuma outra. (TAPSCOTT, 2010, p. 122).

O material didático das disciplinas ministradas pela professora (apostilas digitais e outros) foi disponibilizado através dos blogs e também no sistema acadêmico da instituição.

Gráfico 2: Tecnologias digitais que os alunos gostariam que o professor utilizasse em sala de aula.

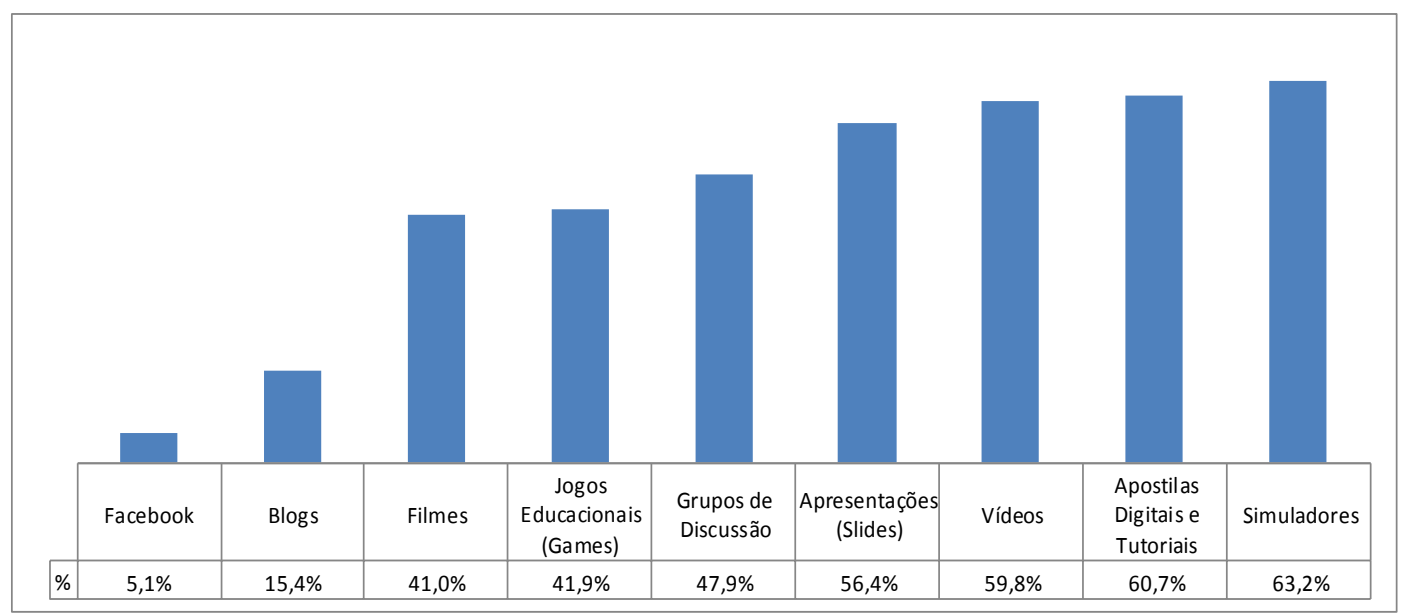

Fonte: dados da pesquisa

\subsection{TDICs utilizadas pelos alunos para complementar os estudos.}

Pela análise do questionário, verificou-se que os alunos da Geração Internet utilizam com frequência as TDICs para complementar seus estudos, sendo que 94,9\% dos respondentes afirmaram que estes recursos colaboraram com seu aprendizado, mas acham indispensável a orientação do professor. Faria (2008) corrobora com este estudo ao afirmar que

[...] não se pode esquecer que os mais poderosos e autênticos "recursos" da aprendizagem continuam sendo o professor e o aluno que, conjunta e dialeticamente, poderão descobrir novos caminhos para a aquisição do saber. (FARIA, 2008, p.44)

Neste contexto, pode-se inferir que o professor orienta a construção do saber mediada pelas TDICs. O gráfico 3 mostra que os alunos gostam de aprender através de aulas presenciais utilizando as TDICs mediadas pelo professor $(75,2 \%)$. Demonstrando assim a importância do papel do professor como orientador na construção do conhecimento. 
Gráfico 3: Como os alunos gostam de aprender.

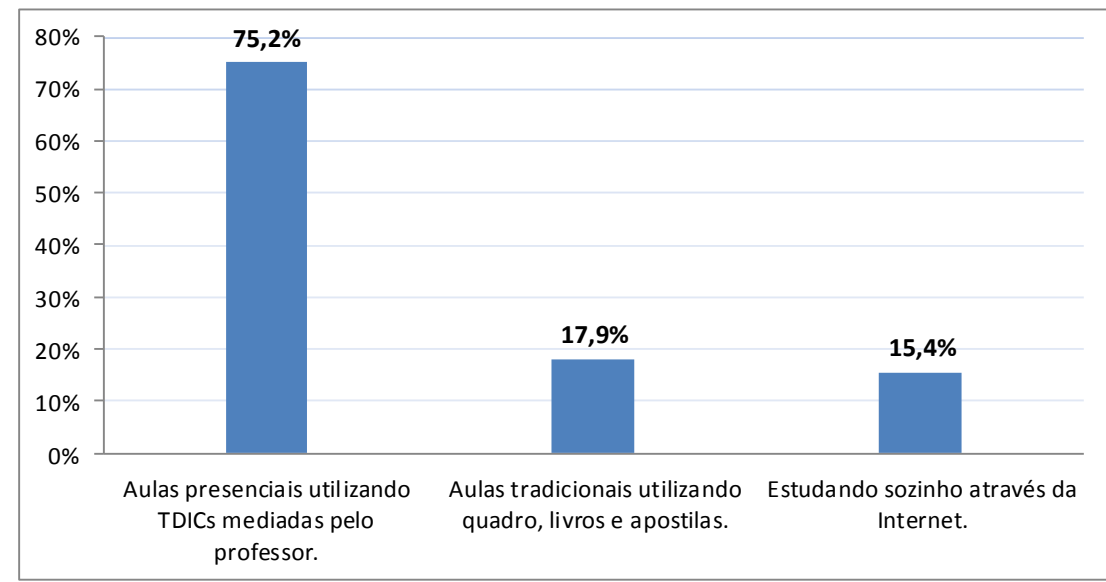

Fonte: dados da pesquisa

O gráfico 4 mostra que os alunos utilizam-se de recursos como apostilas digitais e tutoriais on line $(71,8 \%)$ para complementar os estudos, seguidos de vídeo-aulas $(61,5 \%)$ e sites especializados $(40,2 \%)$. Pode-se inferir através do gráfico que os estudantes da Geração Internet gostam de aprender utilizando-se das TDICs para complementar seus estudos. Tapscott (2010) confirma esta tendência ao afirmar que esses jovens têm aptidão intrigante para tudo o que é digital.

Gráfico 4: Quais tecnologias os alunos utilizam para complementar os estudos.

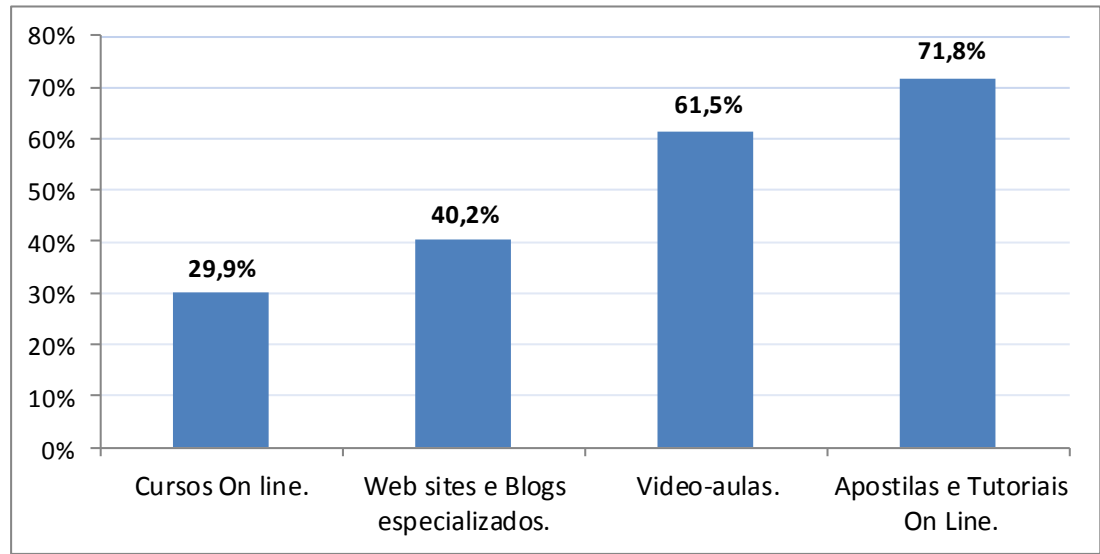

Fonte: dados da pesquisa

\subsection{Tecnologias de comunicação utilizadas para interação aluno/aluno.}

O Gráfico 5 mostra os meios de comunicação mais utilizados pelos alunos para interagir com seus colegas. Estes dados indicam que os Smartphones $(78,6 \%)$ e as redes sociais $(76,9 \%)$ são os meios mais utilizados, evidenciando-se assim a forte necessidade desses jovens se relacionarem mantendo-se conectados. O e-mail aparece com um índice ainda relevante nesta pesquisa $(59,8 \%)$ pelo fato dos alunos utilizarem o e-mail para envio e recebimento de arquivos entre colegas de classe. Prática essa que tem sido substituída pelo armazenamento e compartilhamento de arquivos em nuvem. 
Gráfico 5: Tecnologias utilizadas pelos alunos para interagir com seus colegas.

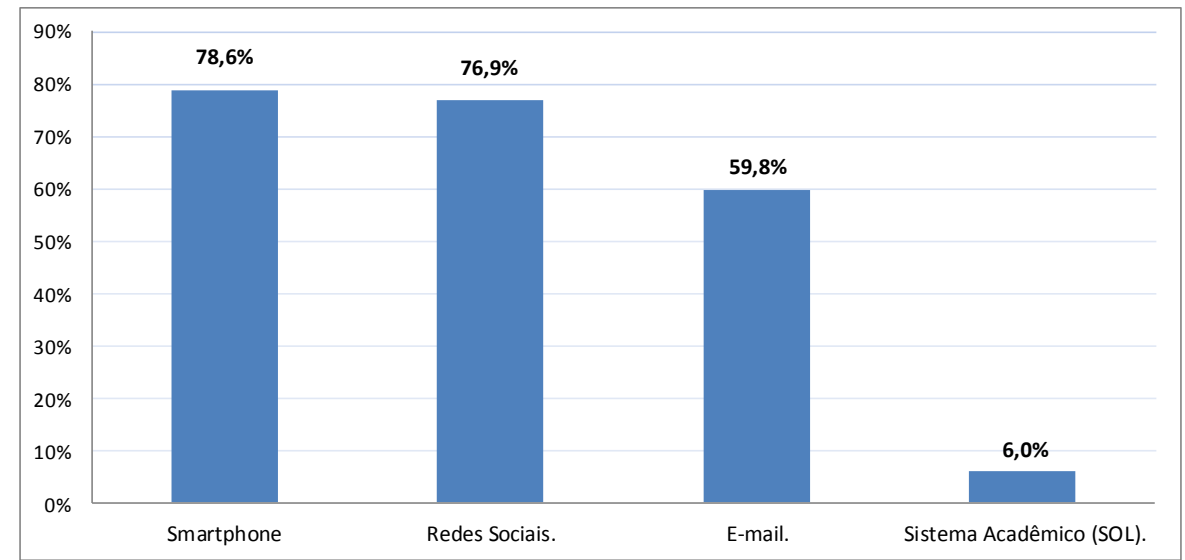

Fonte: dados da pesquisa

\subsection{Tecnologias de comunicação utilizados para interação aluno/professor.}

O gráfico 6 mostra que o meio de comunicação mais utilizado na interação aluno/professor foi o e-mail $(92,3 \%)$, seguido do sistema acadêmico da instituição de ensino (37,6\%), utilizado para disponibilizar material didático digital. Os smartphones $(27,4 \%)$ e as redes sociais $(18,8 \%)$ não são ainda bem aceitos pelos professores.

Gráfico 6: Tecnologias utilizada pelos alunos para interagir com seus professores.

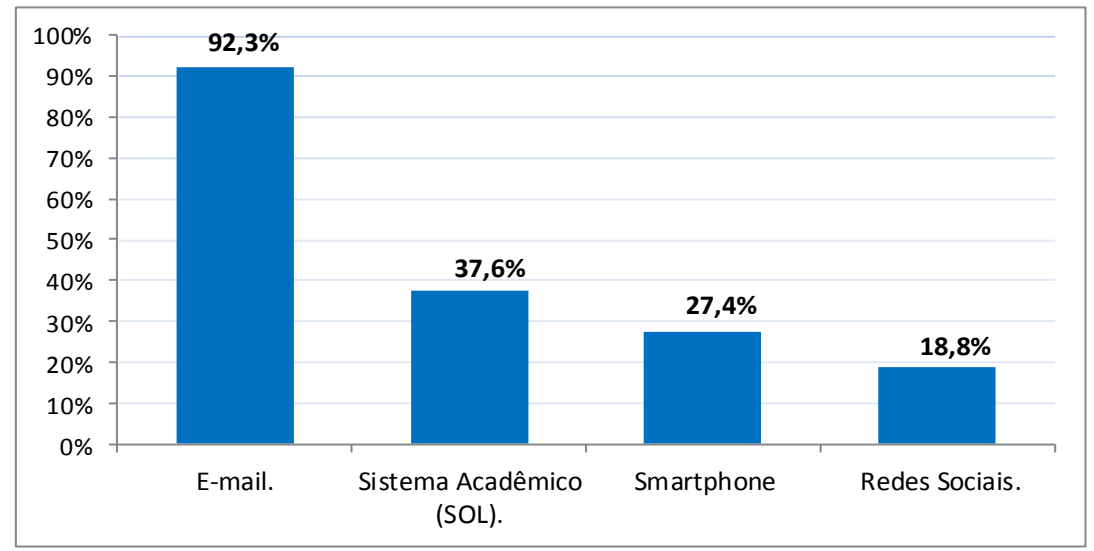

Fonte: dados da pesquisa

\subsection{Percepção dos alunos sobre as aulas presenciais.}

A análise do gráfico 7 vai ao encontro de Kenski (2009), ao afirmar que a escola não se acaba por conta das tecnologias e ainda corrobora ao declarar que o espaço de mediação das TDICs em educação e as pessoas envolvidas no processo - alunos e professores - estão diretamente articulados com os objetivos do ensino e da aprendizagem.

Ainda segundo Kenski (2009), a escola permanece como um espaço para interação entre todos que participam do processo educativo. Nas palavras de Prensky (2010), talvez as escolas sempre existam, mas a sala de aula, como conhecemos hoje, não servirá mais para ensinar. Quando isso vai acontecer, não se sabe. 
Gráfico 7: Como os alunos percebem as aulas presenciais.

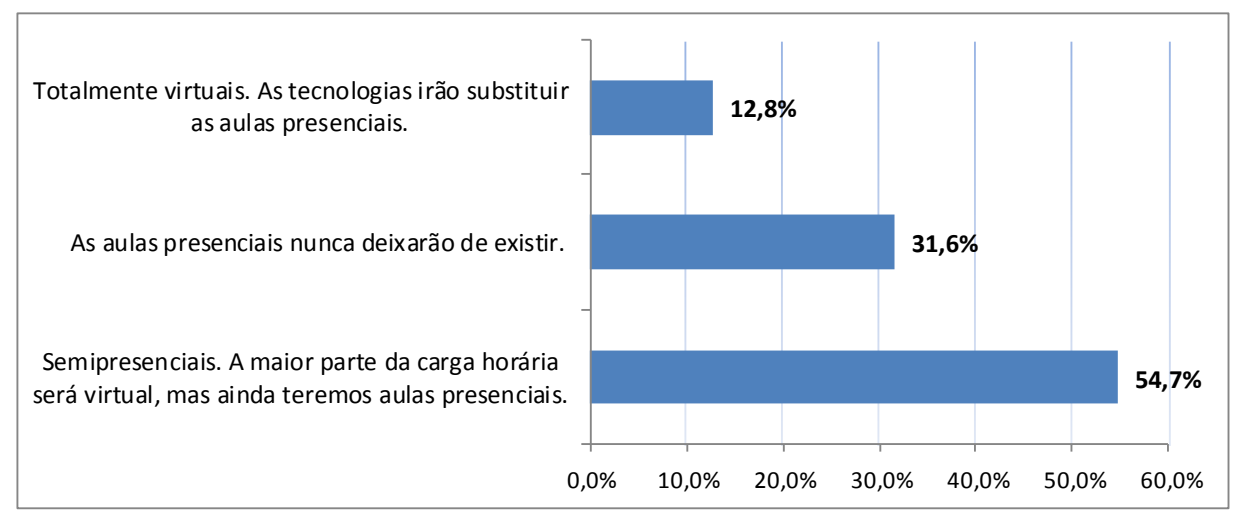

Fonte: dados da pesquisa

Assim, percebe-se o valor da presença do professor atuando como mediador no processo ensino aprendizagem através do uso das tecnologias. Os alunos da Geração Internet acham importante o uso das TDICs pelos professores na sala de aula, entretanto, a pesquisa demonstra que esses professores ainda estão aquém das expectativas dos alunos. Os jovens gostam de aulas interativas utilizando-se de recursos como vídeos, tutoriais e vídeo-aulas on line. Os jovens da pesquisa preferem as aulas presenciais utilizando as TDICs mediadas pelo professor, esses seriam os orientadores e a escola uma espécie de espaço para interação pessoal.

\section{Considerações Finais}

A educação para o século XXI demanda espaços escolares onde os estudantes da Geração Internet utilizem-se das comunidades virtuais para se relacionar e compartilhar informações através da web, o enfoque didático deve promover a construção do conhecimento coletivo mediado pelas tecnologias digitais. A ação docente, antes baseada na autoridade, ganha uma nova perspectiva ao utilizar-se de ambientes colaborativos mediados pelas TDICs.

Os dados aqui expostos reforçam a necessidade de uma análise mais profunda sobre as reais necessidades de mudança do paradigma educacional, visto que o uso das TDICs pelos alunos da Geração Internet é natural. Todos os resultados aqui expostos demonstram que esta geração utiliza de forma expressiva os recursos das tecnologias digitais.

Diante desta realidade, faz-se necessário a atualização permanente dos educadores para o exercício da profissão docente, sendo condição fundamental o domínio de recursos digitais.

Percebe-se através deste estudo, que os jovens da Geração Internet acham importante a presença do professor como mediador da aprendizagem. Professores e alunos trabalhando de forma colaborativa, este é o grande legado das experiências proporcionadas pelas TDICs.

Por fim, sugiro ampliar o uso das práticas pedagógicas aliadas às tecnologias digitais para compreender como se dá a apropriação destas ferramentas pelos alunos bem como investigar o que a geração internet precisa e como os professores podem colaborar para que as atividades em sala de aula se tornem mais interativas.

${ }^{1}$ De acordo com o Instituto Brasileiro de Opinião Pública e Estatística - IBOPE (2010) as gerações do Brasil se dividem em Baby Boomers (acima de 46 anos), Geração X (30 a 45 anos), Geração Y (20 a 29 anos)e Geração Z (12 a 19 anos). 


\section{Referências Bibliográficas}

CASTELLS, Manuel. A sociedade em rede. A era da informação: economia, sociedade e cultura. Vol. I. São Paulo: Paz e Terra, 2000.

COLL, César; MONEREO, Carles (Orgs.). Psicologia da educação virtual Aprender e Ensinar com as Tecnologias da Informação e da Comunicação. Porto Alegre: Artmed, 2010.

FARIA, Elaine Turk; ENRICONE, Délcia (Org.). O professor e as tecnologias educacionais. Capítulo publicado no livro: Ser Professor. Porto Alegre: Ed. 6, EDIPUCRS, 2008.

IBOPE. Geração Y e Z: Juventude Digital. Disponível em: <http://www4.ibope.com.br/download/geracoes\%20_y_e_z_divulgacao.pdf> Acesso em: 17 abr. 2016

KENSKI, Vani Moreira. Tecnologias e Ensino Presencial e a Distância. São Paulo: Papirus Editora. Ed. 3, 2003. 160 p.

Educação e Tecnologias: o novo ritmo da informação. São Paulo: Papirus Editora. Ed. 5, 2009. 133 p.

LÉVY, Pierre. Cibercultura. São Paulo: Ed. 34,1999. 264 p.

MACHADO, S. C. Uso das TDICs como recurso pedagógico no curso técnico de informática. Congresso de Inovação e Metodologias de Ensino, UFMG (2015). $<$ https://congressos.ufmg.br/index.php/congressogiz/congresso-giz2015/paper/view/42/76> Acesso em 30 Out. 15.

MORAN, José Manuel. A educação que desejamos: novos desafios e como chegar lá. São Paulo: Papirus educação. Ed. 5,2015

O vídeo na sala de aula. Revista Comunicação e Educação. São Paulo, ECAEd. Moderna. Jan/Abr de 1995.

<http://www.revistas. usp.br/comueduc/article/viewFile/36131/38851> Acesso em: 15 mai. 2015.

O'REILLY, Tim. What Is Web 2.0. O'Reilly, 2005. Disponível em: $<$ http:/www.oreilly.com/pub/a/web2/archive/what-is-web-20.html?page=2> Acesso em: 10 abr. 2015

PRENSKY, Marc. Digital natives, digital immigrants. On the horizon, NCB University Press, v. 9, n. 5, Oct. 2001. Disponível em: <http://www.marcprensky.com /writing/Prensky\%20-\%20Digital\%20Natives, \%20Digital\%20Immigrants\%20\%20Part1.pdf> Acesso em: 17 mai. 2015

The Role of Technology in teaching and the classroom. Published in Educational Technology, Nov-Dec 2008. Disponível em: $<$ http://www.marcprensky.com/writing/Prensky-The_Role_of_Technology-ET-11-1208.pdf> Acesso em: 14 abr. 2015.

TAPSCOTT, Don. A hora da geração digital. Rio de Janeiro: Nova Fronteira, 2010. $417 \mathrm{p}$. 